\title{
BR_PITGAM (Banco Relacional de Padrões de Interface de Top Games para Mobile), desenvolvimento da ferramenta de avaliação de jogabilidade, ergonomia e interatividade em elementos de design de interface sensoriais de jogos digitais
}

BR_PITGAM (Relational Bank of Top Games Standards Interface for Mobile), development of the assessment tool linking gameplay, ergonomics and interactivity in sensory interface design elements of digital games

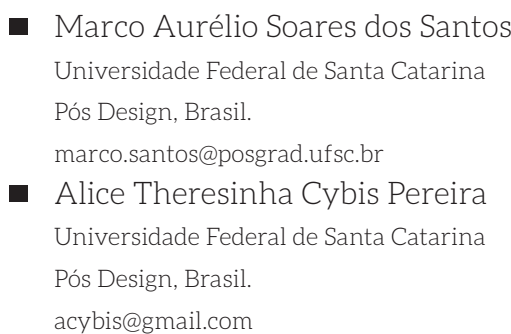

\begin{abstract}
This paper aims to describe the development process of BR_PITGAM Tool (Relational Bank of Top Games Standards Interface for Mobile). New experiences in digital games are observed in different genres, types of interaction and navigation. However they can be difficult to follow and related as scientific contributions are treated in general and dispersed form. The BR_PITGAM tool that aims to relate the recommendations for gameplay, ergonomics and interactivity with the interface elements, resulting in a body of knowledge capable of assisting the learning process of digital games. As a relational bank, the proposed tool enable the identification of sensory interface design patterns in casual digital games for smartphones. Thus it offers a new theoretical framework for future research in the area and enables access to various relationships according to desired approaches.
\end{abstract}

Keywords: Interface Design, Gameplay, Ergonomics, Interactivity, Digital Games

\section{Introdução}

Este artigo apresenta o conteúdo da Ferramenta de avaliação de design de interface BR_PITGAM (Banco Relacional de Padrões de Interface de Top Games para Mobile), descrevendo as fases de seu desenvolvimento com ênfase no levantamento na literatura, síntese de recomendações para cada área pesquisada e definição do grupo de jogadores avaliadores.

$\mathrm{O}$ intenso crescimento do mercado de jogos digitais para o mercado mobile tem proporcionado constantes inovações, dada à tamanha audiência e desempenho dos dispositivos que tem influenciado significativamente na economia do entretenimento. Novas experiências de jogos digitais são criadas e observadas em diferentes gêneros, tipos de interação e navegação que podem ser difíceis de serem acompanhadas e relacionadas uma vez que as contribuições científicas na área são tratadas de forma geral e dispersas. A produção deste estudo deve-se a diferentes recomendações de análise encontradas na literatura da área de ergonomia, design interface, interatividade e jogabilidade. Estas recomendações compõem uma ferramenta de análise de estímulos individuais ou coletivos em interfaces de jogos digitais. Neste contexto, surge a Ferramenta BR_PITGAM que tem por objetivo o desenvolvimento de um banco relacional incorporando recomendações de jogabilidade, ergonomia e interatividade associadas aos elementos de interface, tendo como resultado um conjunto de conhecimentos capazes de identificar padrões de design de interface sensoriais em jogos digitais casuais para smartphones.

Neste sentido observa-se que o produto deste estudo tem potencial para ser aplicado no processo de ensino e aprendizagem para o desenvolvimento de interfaces sensoriais em jogos digitais para mobile. Assim como possibilitar a identificação e relação de elementos padrões em interface de jogos digitais de grande aceitação através de consulta ao banco relacional disponibilizado pela ferramenta .

Segundo, Pereira e Gonçalves (2010), o projeto de desenvolvimento em hipermídia exige definição dos elementos que compõem o design de interface, os quais podem ser orientados pelo framework proposto por Garret (2011). Este propõem 5 planos que permitem o desenvolvimento de um projeto de interfaces orientados em conceitos para abordagem 
de problemas relacionados a experiência do jogador. Estes planos permitem a evolução do projeto do mais abstrato ao concreto. Os planos referem-se a estratégia, escopo, estrutura, esqueleto e superfície.

Este framework compartilha da idéia que o desenvolvimento da interface deve ser orientado para a experiência do usuário. Assim, no universo dos jogos digitais, a preocupação deve ser com a experiência do jogador que requer conhecer bem seu perfil, as especificações funcionais dos dispositivos, e as informações essenciais que devem ser compartilhadas para que o jogador jogue em diferentes níveis.

Desta forma, permitiu-se contextualizar de forma análoga ao universo dos jogos digitais, o framework de Garret para orientar o conteúdo da ferramenta, conforme a Figura 1.

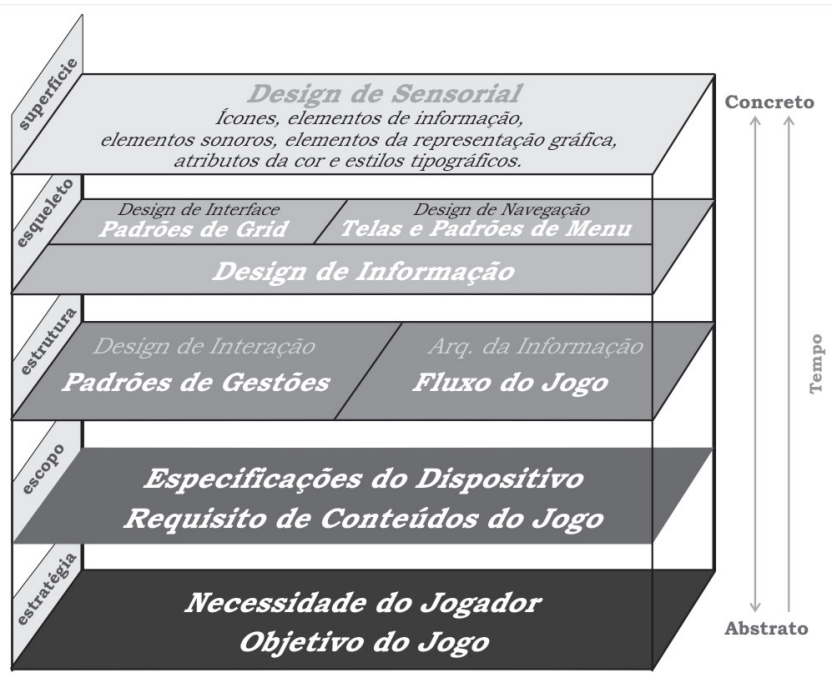

Figura 1: Framework de conceitos para abordagem de problemas relacionados a experiência do jogador. Fonte: adaptado de Garret (2011) para projeto de design de interface de jogos digitais.

\section{Metodologia}

As fases iniciais do estudo contemplaram o planejamento das atividades relacionadas ao desenho da pesquisa (Braviano, 2005).

Inicialmente, identificou-se a natureza da pesquisa que se deu de forma exploratória para que se pudesse ter uma visão geral dos fatos, aprofundar os conceitos sobre tema e reunir os fundamentos deste estudo. Quanto ao emprego dos procedimentos técnicos, a investigação foi por meio de estudos de casos. Assim, o desenvolvimento da Ferramenta, quanto a pesquisa, seguiu as seguintes fases:

a) Primeira Fase - Levantamento na literatura: esta etapa tratou do tema processo de design centrado no usuário com base no modelo proposto por Garrett (2011), que foi fundamental para organizar todos os conhecimentos incorporados na Ferramenta de forma a considerar do nível mais concreto ao mais abstrato da experiência do usuário, sobre jogabilidade, ergonomia, interatividade e design de interface na busca por recomendações aplicáveis ao design em jogos digitais casuais para smartphones.

b) Segunda Fase - síntese de recomendações para cada área pesquisada a ser avaliada: como fontes de referência que fizeram parte da pesquisa bibliográfica os seguintes autores e tema: Rogers (2010), design de Jogo, com definições quanto elementos da interface do jogo, posição da câmera, tela de jogo e tipos de ícones; Rabin (2011), uma visão geral dos gêneros de jogos; Saffer (2008), design em interfaces gestuais; Samara (2010), com diferentes tipologias de grids; Neil (2012), padrões de menu para navegação; Fagerholt (2009), identificação dos elementos de interface e Whitmore (2003), classificação do elementos sonoros com base na diegese; Perassi (2010), classificação dos elementos de representação gráfica; Barros (2006), Farina (2006), Fraser (2007), Pedrosa (2009), atributos da cor; Dixon (1995), classificação dos estilos tipográficos; Fontoura (2015), tipografia e legibilidade; Schell (2011), princípios de design de jogos: as "lentes; Bastien (1993) os critérios ergonômicos para avaliação de interface;

c) Terceira Fase - Definição do grupo de jogadores: os membros do grupo que fizeram parte da $1^{\text {a }}$ fase de desenvolvimento da ferramenta $\mathrm{Br}$ _Pitgam, que participaram das discussões em torno dos conteúdos e ajudaram a lapidar as questões incorporadas na ferramenta era composto por seis estagiários voluntários em fase adiantada na matriz curricular, do $5^{\circ}$ e $7^{\circ}$ período da disciplina de estágio com carga horária de sessenta horas, do Curso de Design de Jogos e Entretenimento Digital, com idade entre 17 e 22 anos.

d)Quarta Fase-Seleçãoda amostra:os jogos digitaiscasuais para smartphones colaboraram para o desenvolvimento da ferramenta a partir das suas propriedades observadas e a grande aceitação no mercado de jogos digitais. Estabeleceuse como critério de seleção o maior número de acessos/ instalações (superior ou igual 1.000.000), grande aceitação junto ao mercado (com pontuação acima 4.0 pontos de uma escala de 0 a 5 pontos) e com disponibilidade gratuita. A amostra foi composta por 26 jogos digitais para o sistema operacional android, selecionados na loja virtual google play. Sendo estes: Fruit Ninja, Zombie Tsunami, Shadow Fight 2, Pocket Mine, Angry Birds Stella, Temple Run 2, Subway Surf, Meu Malvado Favorito, Pou, Gen Miner, Era do Gelo, Plants vs Zombies 2, Don't Tap The White Tile, Infectonator, Air Control Lite, Trial Xtreme 3, Drag Racing, Angry Birds Epic, Clash of Clans, Cand Crush Saga, Cut the Rope 2, Perguntados, Bubble Blaze, Where's My Water? 2, Paperama, Hay Day.

e) Quinta Fase - Elaboração da ferramenta: criou-se o Design de Interface do Banco de Dados Relacional, através do planejamento e a organização dos conhecimentos relacionados e descritos na primeira etapa, tendo por base Garrett (2011), e na síntese de recomendações para cada área pesquisada para formulação dos enunciados das questões com respostas de múltipla escolha, com os conteúdos explicativos tendo base os autores pesquisados a partir da segunda fase. Incialmente foi elaborado um desenho organizando os conteúdos. Utilizou-se a ferramenta de formulários online 
Google Docs, como forma de incorporação de conhecimentos e entrada de dados das respostas obtidas a partir das avaliações da amostra selecionada. Tais, avaliações realizadas nos jogos digitais selecionados e os dados obtidos fazem parte da sexta fase alvo de futuro artigo.

Este artigo descreve a síntese de recomendações que compõem o Br_Pitgam em sua versão alpha.

\section{Resultados}

Com a finalidade de atender ao objetivo de relacionar o conjunto de recomendações com os elementos de interface possibilitando a identificação de padrões, o Br_Pitgam foi divido em três etapas, onde os planos proposto por Garrett (2011), foram distribuídos, ao longo da ferramenta.

Segue a descrição das três etapas com a distribuição dos conteúdos da ferramenta orientados por, Garrett (2011):

$1^{\text {a }}$ Etapa: buscou conhecer necessidades do jogador e o objetivo do jogo, seguiu-se o plano da estratégia.

Plano da Estratégia: o plano foi constituído de um conjunto de questões de múltipla escolha com o propósito de obter dados mais concretos das necessidades/perfil do jogador, como: nome; e-mail; sexo; Em que área pretende atuar; Com que frequência você joga na semana? Quantas horas em média você joga por dia? Qual a $1^{\text {a }}$ plataforma que você mais joga? (para esta resposta foram identificadas, atualmente, vinte e quatro plataformas disponíveis para jogos: mac, ios, windows, windows/steam, windows/origin, linux, linux/steam, xbox 360, ps2, ps vita, ds, 3ds, wii, wii u, tablet, smartphone, navegador, ouya, amazon fire tv, analógicos). Qual a $2^{a}$ plataforma que você mais joga? Qual a $3^{\text {a }}$ plataforma que você mais joga? Qual o seu $1^{\circ}$ gênero preferido? (para esta resposta foram identificados, atualmente, vinte gêneros diferentes de jogos digitais: ação, arcade, aventura, quebra-cabeças, rpg, simulação, mmos, trivia, running, plataforma, moba/rts, corrida, educativo, esporte, estratégia, família, música, fps, luta, sandbox). Qual o seu $2^{\circ}$ gênero preferido? E a pergunta final, de natureza subjetiva: Para você qual o principal motivo para se jogar games?

$2^{\text {a }}$ Etapa: registrou as especificações do dispositivo utilizado durante a avaliação e a busca pela identificação dos padrões de elementos de informação presentes na amostra de jogos determinou-se:

Plano do Escopo: (as especificações funcionais do dispositivo e os requisitos do conteúdo do jogo selecionado) foi constituído de um conjunto de questões abertas, e de múltipla escolha na maioria, a fim de registrar as especificações funcionais do dispositivo, assinalando: tipo de dispositivo (sendo quinze modelos de Smartphone e onze modelos de tablets), tamanho de tela em polegadas, resolução de tela em pixel (para este resposta foram identificados, atualmente, quatorzes tipos resolução: 240x320, 320x480, 480x800,
$854 \times 480,960 \times 480,960 \times 540,1136 \times 640,1280 \times 720,1280 \times 800$, 1024x600, 1024x768, 1280x800, 1920x1080, 2048x1536), sistema operacional (identificou-se cincos sistemas: Android, iOS, Windows Phone, Black Berry, Symbian), e os requisitos do conteúdo do jogo identificando: o nome do jogo, gênero, disponibilidade (gratuito, pago), pontuação no ranking, número de instalações, data de atualização e características do Jogo; Constituiu-se, também, deste plano as especificações funcionais do jogo selecionado, quanto ao tipo de plano de projeção (Ortográfico / 2D e Perspectiva / 3D). Quanto aos diferentes tipos de posicionamento de câmera (Rogers, 2010), foram identificados nove tipos: estática, câmera de rolagem, $1^{\text {a }}$ pessoa, $3^{\mathrm{a}}$ pessoa, hybrid / $2.5 \mathrm{~d}$, isométrico, de cima para para baixo, de cima para baixo e de lado e rolagem paralax; A fim de facilitar a identificação, as resposta são acompanhadas de imagens referenciais para cada um dos tipos de posicionamento de câmera, conforme a Figura 2.

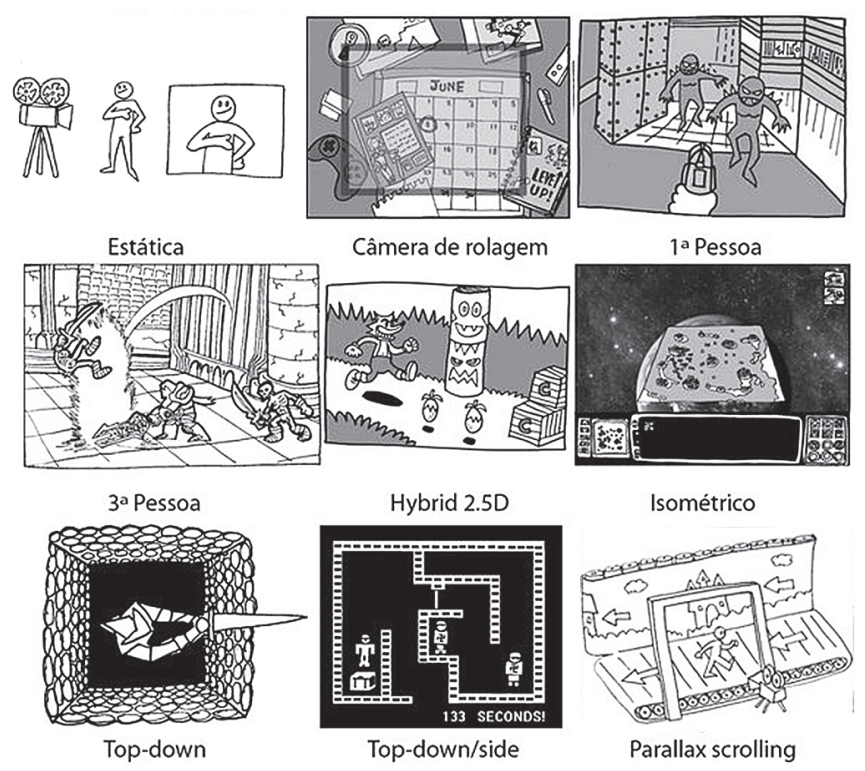

Figura 2: Tipos de posicionamento de câmera. Fonte: Rogers (2010).

O Plano da Estrutura: relacionado ao design de interação e a arquitetura da informação. A ferramenta incorporou o design de interação por meio de diferentes padrões de interação tátil/gestual. Optou-se pelo formato da resposta de múltipla escolha para identificar na amostra selecionada os nove diferentes padrões de gestos apresentados por Saffer (2008), sendo estes: tap, double tap, drag swipe, pinch open, pinch close, long press, double touch; A fim de facilitar a identificação, as resposta são acompanhadas de imagens referenciais para cada um dos padrões de gestos, conforme a Figura 3. 


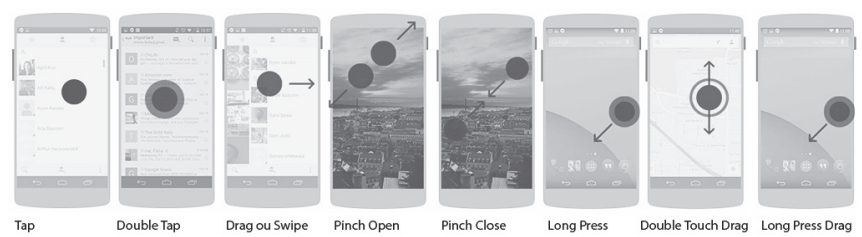

Figura 3: Padrões de gestos para mobile. Fonte: google.

A identificação da arquitetura da informação compreendida através do fluxo das telas de jogo, disponíveis ao jogador, não foi identificada pelo Br_Pitgam.

O Plano do Esqueleto: compreende o design de informação (design de interface e design de navegação). que por sua vez, tem a finalidade de planejar o conteúdo da interface do jogo, disponibilizando ao jogador, o acesso à informação de forma prática e segura. Optou-se pelo formato da resposta de múltipla escolha para identificar na amostra selecionada os quatro diferentes padrões de grids apresentados por Samara (2010), sendo estes: grid retangular, grid de colunas, grid modular e o grid hierárquico; A fim de facilitar a identificação, as resposta são acompanhadas de imagens referenciais para cada um dos padrões de grids, conforme a Figura 4
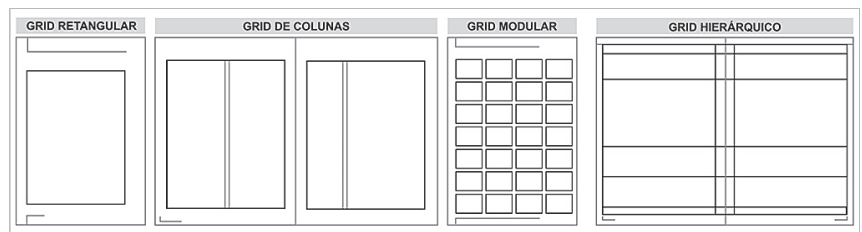

Figura 4 - Padrões de grid. Fonte: Samara (2010).

Também, para identificar os vinte diferentes tipos de telas apresentados por Rogers (2010), sendo estas: tela de carregar, tela de início, tela de calibração, tela de controles, tela de opções, tela de avatar, tela de seleção de nível, tela de tutorial, tela de jogo, tela de inventário, tela de pause, tela de nível completo, tela de recompensas, tela de loja, tela de créditos, tela de fim de jogo, tela de resultado da partida, tela de salvar, tela de social e a tela de direitos autorais. E, a identificação de sete padrões primários de navegação, segundo Neil (2012): menu springboard, menu de lista, menu de abas, menu de galeria, menu de dashboard, menu de metáfora, megamenu e outra; A fim de facilitar a identificação, as resposta são acompanhadas de imagens referenciais para cada um dos padrões, conforme a Figura 5.

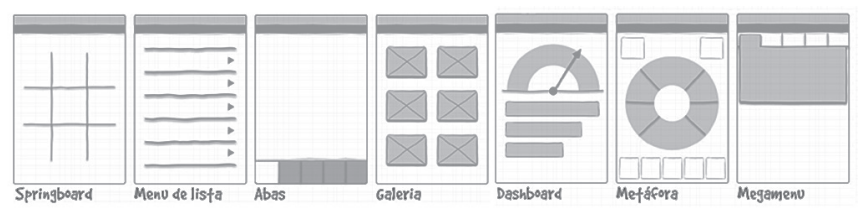

Figura 5: Padrões primários de navegação. Fonte: Neil, (2012).
O Plano da Superfície: relacionado ao design sensorial. A ferramenta buscou incorporar, de forma geral, um conjunto conhecimentos da área do design visual/sensório. Optou-se pela formulação de questões no formato resposta de múltipla escolha, e aberta para identificar na amostra selecionada os diferentes padrões:

a) Padrões de ícones, apresentados por Rogers (2010): vida, localização do alvo, munição, inventário, resultado, mapa/ radar, sinal de alerta e outro; A fim de facilitar a identificação, as resposta são acompanhadas de imagens referenciais para cada um dos tipos de ícones, conforme a Figura 6:

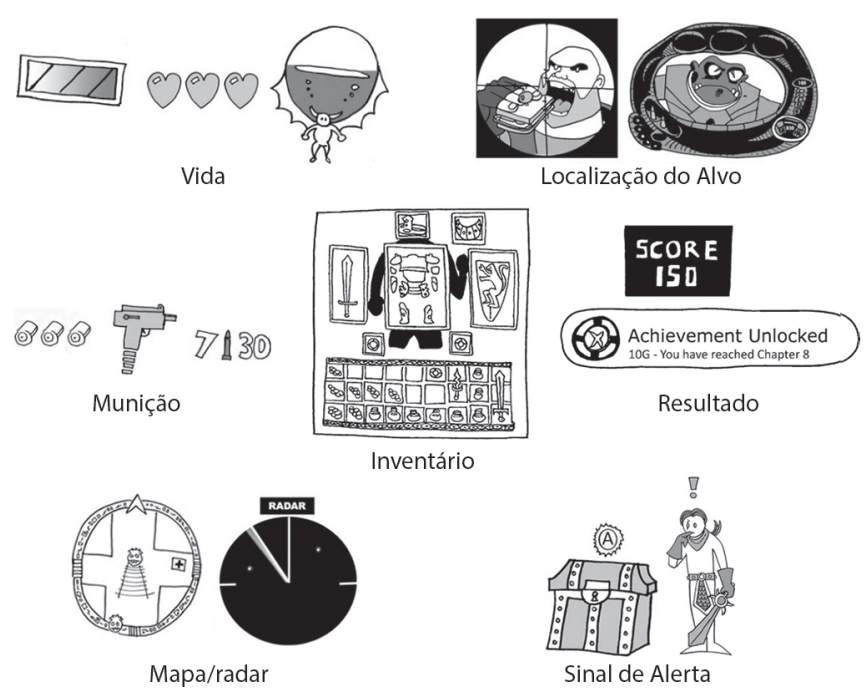

Figura 6: Tipos de ícones encontrados na interface do jogo. Fonte: Rogers (2010).

b) Padrões de elementos de informação, apresentada por Saunders (2013): não diegético, diegético meta-perceptível e espacial.

c) Padrões de Elementos Sonoros, apresentada por Whitmore (2003): Aúdio: interativo, adaptativo, procedural - Interação: direta, indireta, ambiental - Som com base na diegese: diegético, não-diegético ou extra diegético, metadiegeticas e extra ficcional.

d) Classificação de elementos de representação gráfica apresentada por Perassi (2010): simbólica/geometrizada, naturalista/humanizada, expressionista/abstrata; A fim de facilitar a identificação, as resposta são acompanhadas de imagens referenciais para cada uma das representações visuais, conforme a Figura 7.

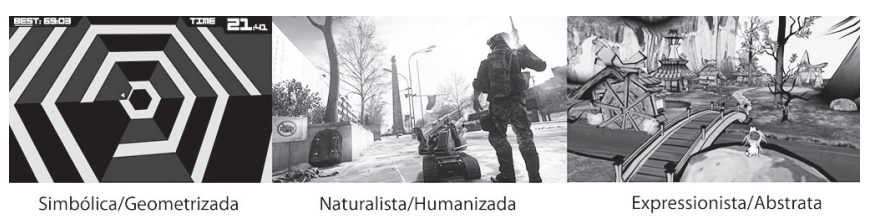

Figura 7: Classificação dos Elementos de representação gráfica em em Design de Informação segundo Perassi (2010). Fonte: elaborado pelo autor. 
e) Atributos da cor, baseada em Farina (2006), Fraser (2007), Pedrosa, (2009): Temperatura da cor: quente, fria, acromática - Escala de Valores de índices de luminosidade das imagens coloridas ou incolores: valor alto, valor médio, valor baixo - Pureza da cor: saturada, dessaturada.

f) Estilos tipográficos, baseado na classificação apresentada por Dixon (1995): góticas, humanistas, garaldinas, transicionais, didônicas, serifa quadrada, sem serifa grotescas, sem serifa neo-grotescas, sem serifa geométricas, sem serifa humanistas, sem serifa problemas, serifa triangular, caligráficas, ornamentais, processadas/manipuladas, sampleadas, emulativas, curvilíneas, dingbats/símbolos/ ornamentos; A fim de facilitar a identificação, as resposta são acompanhadas de imagens referenciais para cada um dos estilos tipográficos, conforme a Figura 8.

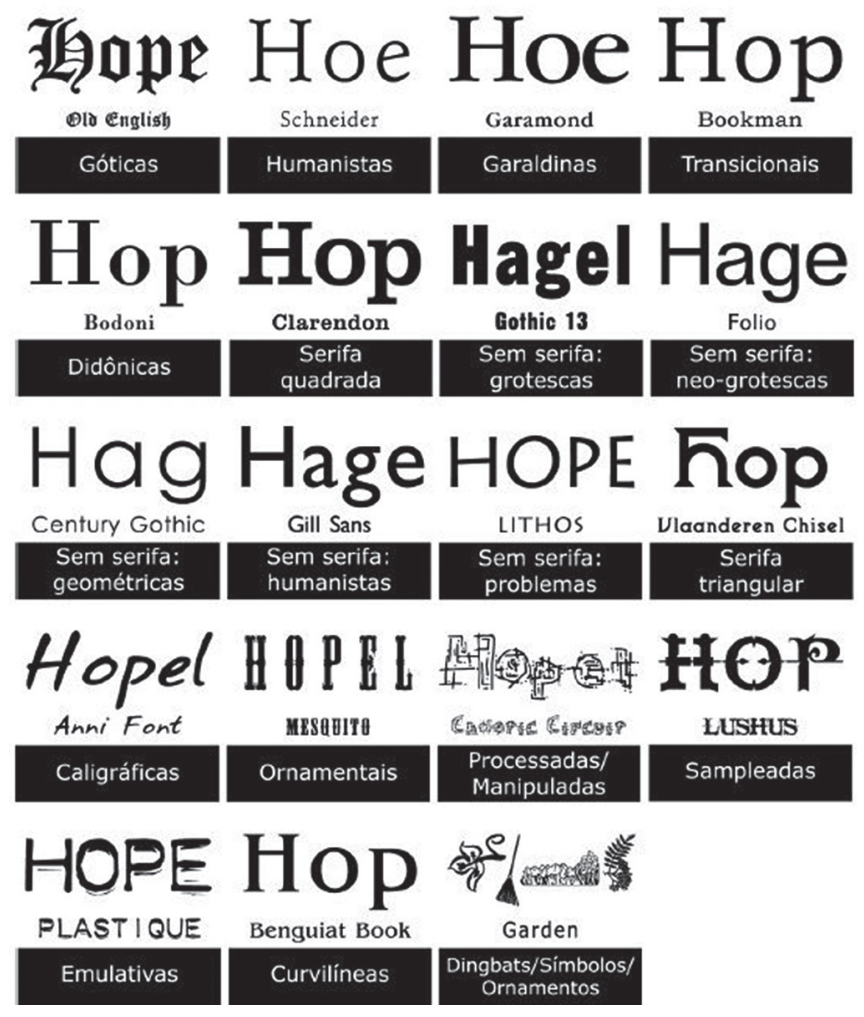

Figura 8: Sistema de Classificação dos Tipos Caligráficos. Fonte: Dixon (1995).

g) Legibilidade, segundo as recomendações apresentadas por Fontoura (2015), para avaliar a legibilidade da fonte aplicada na interface do jogo, de forma geral, a questão foi formulada com respostas de múltipla escolha, utilizando a escala likert com valores entre ruim, regular, bom, muito bom e excelente, tamanho das letras, espacejamento, peso comprimento da linha, contraste figura/fundo.

Assim, encerraram-se os conteúdos incorporados ao plano da superfície, dando início as questões de respostas abertas para avaliação dos conhecimentos de Jogabilidade, Ergonomia e Interatividade que são apresentados na $3^{\text {a }}$ Etapa da ferramenta.

$3^{\text {a }}$ Etapa: incorporou questões objetivas e subjetivas para avaliação da amostra em relação a um conjunto de recomendações de jogabilidade, ergonomia e interatividade, com a formulação de questões com respostas de múltipla escolha, utilizando a escala likert com valores entre (ruim, regular, bom, muito bom e excelente) e respostas aberta para que jogador comentasse em que momentos ficou evidente tal observação apontada;

A Jogabilidade foi avaliada com base nas recomendações apresentados por Shell (2010), conforme quadro 1.

\begin{tabular}{|c|c|}
\hline Recomendações & Conceito \\
\hline Experiência Essencial & $\begin{array}{l}\text { Esta lente consiste em } \\
\text { parar de pensar no seu jogo } \\
\text { e comece a pensar sobre } \\
\text { a experiência do jogador. } \\
\text { Pergunte-se: } \\
\text { 1. Qual experiência, desejo } \\
\text { que o jogador tenha? } \\
\text { 2. O que é essencial } \\
\text { para essa experiência? } \\
\text { 3. Como meu jogo pode } \\
\text { captar essa essência? }\end{array}$ \\
\hline Surpresa & $\begin{array}{l}\text { Agregue ao jogo surpresas } \\
\text { interessantes. Pergunte-se: } \\
\text { 1.O que irá surpreender os } \\
\text { jogadores quando jogarem } \\
\text { meu jogo? } \\
\text { 2. A história no meu jogo } \\
\text { tem surpresas? As regras } \\
\text { do jogo as têm? E o trabalho } \\
\text { artístico? E a tecnologia? } \\
\text { 3. Suas regras dão aos } \\
\text { jogadores maneiras de } \\
\text { surpreender um ao outro? } \\
\text { 4.Suas regras dão aos } \\
\text { jogadores maneiras de } \\
\text { surpreender a si próprios? }\end{array}$ \\
\hline Diversão & $\begin{array}{l}\text { Diversão é desejável em } \\
\text { quase todos os jogos. } \\
\text { Pergunte-se: } \\
\text { 1.Quais são as partes } \\
\text { divertidas do meu jogo? Por } \\
\text { quê? } \\
\text { 2.Que partes precisam ser } \\
\text { mais divertidas? }\end{array}$ \\
\hline
\end{tabular}




\begin{tabular}{|c|c|}
\hline Curiosidade & $\begin{array}{l}\text { Pense sobre as reais } \\
\text { motivações do jogador - } \\
\text { não apenas nos objetivos } \\
\text { definidos para seu jogo, } \\
\text { mas na razão pela qual o } \\
\text { jogador quer alcançar esses } \\
\text { objetivos. Pergunte-se: } \\
\text { 1. Quais questões meu jogo } \\
\text { estabelece na mente do } \\
\text { jogador? } \\
\text { 2.O que estou fazendo para } \\
\text { que eles se importem com } \\
\text { essas questões? } \\
\text { 3.O que posso fazer para que } \\
\text { criem ainda mais questões? }\end{array}$ \\
\hline Valor Endógeno & $\begin{array}{l}\text { Pense em como os jogadores } \\
\text { se sentem em relação a } \\
\text { itens, objetos e pontuação } \\
\text { no jogo. Pergunte-se: } \\
\text { 1. O que é valioso para os } \\
\text { jogadores no meu jogo? } \\
\text { 2. Como posso torná-lo } \\
\text { mais valioso para eles? } \\
\text { 3. Qual é a relação entre } \\
\text { o valor no jogo e as } \\
\text { motivações do jogador? }\end{array}$ \\
\hline S olução de Problemas & $\begin{array}{l}\text { Todo jogo deve propor um } \\
\text { grau de situações problemas, } \\
\text { a resolução das mesmas, } \\
\text { deve representar sucesso } \\
\text { e oferecer recompensas, } \\
\text { então se pergunte: } \\
1 \text { Quais problemas meu jogo } \\
\text { solicita que o jogador resolva? } \\
\text { 2. Há problemas ocultos a } \\
\text { resolver que surgem como parte } \\
\text { do ato de jogar? }\end{array}$ \\
\hline
\end{tabular}

Quadro 1: Conjunto de recomendações essenciais que avaliou a qualidade da jogabilidade oferecida ao jogador. Fonte: recomendações de jogabilidade apresentadas por SHELL (2011).

A Ergonomia foi avaliada com base na qualidade das recomendações apresentados por BASTIEN e SCAPIN (1993), contextualizando-as de forma análoga ao universo dos jogos digitais, conforme quadro 2.

\begin{tabular}{|l|l|}
\hline \multicolumn{1}{|c|}{ Recomendações } & \multicolumn{1}{c|}{ Conceito } \\
\hline Presteza & $\begin{array}{l}\text { Avaliou a presteza quanto } \\
\text { a orientação ao jogador em } \\
\text { ações como entrada de dados, } \\
\text { informando o contexto em } \\
\text { que se encontra, bem como } \\
\text { dispondo de um sistema de } \\
\text { ajuda e modo de acesso para } \\
\\
\\
\text { conduzí-lo durante as suas } \\
\text { ações no game. }\end{array}$ \\
\hline
\end{tabular}

\begin{tabular}{|c|c|}
\hline $\begin{array}{l}\text { Agrupamento/Distinção por } \\
\text { Localização }\end{array}$ & $\begin{array}{l}\text { Avaliou o posicionamento } \\
\text { relativo dos elementos de } \\
\text { interface indicando se eles } \\
\text { pertencem ou não a um } \\
\text { grupo, suas diferenças e o } \\
\text { posicionamento relativo dos } \\
\text { mesmos dentro de um grupo. }\end{array}$ \\
\hline $\begin{array}{l}\text { Agrupamento/Distinção por } \\
\text { Formato }\end{array}$ & $\begin{array}{l}\text { Avaliou às características } \\
\text { gráficas (formato, cor, linha, } \\
\text { textura, volume, iluminação) } \\
\text { que indicam se itens pertencem } \\
\text { ou não a um grupo, suas } \\
\text { distinções entre grupos } \\
\text { diferentes ou distinções entre } \\
\text { itens de um dado grupo. }\end{array}$ \\
\hline Feedback Imediato & $\begin{array}{l}\text { Avaliou a qualidade do sistema } \\
\text { em fornecer as respostas } \\
\text { de forma rápida às ações do } \\
\text { jogador. Devem ser adequadas } \\
\text { e consistentes para cada tipo de } \\
\text { ação. Tais entradas podem ir do } \\
\text { simples pressionar de uma tecla } \\
\text { até a sinalização de progressão } \\
\text { com informações sobre ação e } \\
\text { seu resultado. }\end{array}$ \\
\hline Condução & $\begin{array}{l}\text { Avaliou, de forma geral, a } \\
\text { qualidade das orientações, } \\
\text { informações, e condução de } \\
\text { ações do usuário na interação } \\
\text { com o game. }\end{array}$ \\
\hline Concisão & $\begin{array}{l}\text { Avaliou a facilidade de } \\
\text { perceber e reconhecer } \\
\text { as entradas e saídas de } \\
\text { informações no jogo. }\end{array}$ \\
\hline Ações Mínimas & $\begin{array}{l}\text { Avaliou a capacidade do jogo de } \\
\text { diminuir ao máximo a carga de } \\
\text { trabalho do jogador em relação } \\
\text { a realização de tarefas. }\end{array}$ \\
\hline Densidade Informacional & $\begin{array}{l}\text { Avaliou a densidade } \\
\text { informacional mostrada ao } \\
\text { jogador em relação a todos os } \\
\text { conjuntos de informações e } \\
\text { itens. Levando em consideração } \\
\text { a concisão. }\end{array}$ \\
\hline Carga de trabalho & $\begin{array}{l}\text { Avaliou a qualidade do jogo em } \\
\text { minimizar o conjunto da carga } \\
\text { de trabalho na realização das } \\
\text { tarefas, levando em conta a } \\
\text { experiência do jogador }\end{array}$ \\
\hline Ações Explícitas & $\begin{array}{l}\text { Avaliou o quão clara são } \\
\text { demonstradas as ações do } \\
\text { jogador no jogo. }\end{array}$ \\
\hline
\end{tabular}




\begin{tabular}{|c|c|}
\hline Controle do Usuário & $\begin{array}{l}\text { Avaliou o grau de controle que } \\
\text { o jogador tem sobre a execução } \\
\text { dos processos do jogo. }\end{array}$ \\
\hline Controle Explícito & $\begin{array}{l}\text { Avaliou, de forma geral, avalie } \\
\text { o grau de controle dos processos } \\
\text { do jogo e quão explícito se } \\
\text { apresentam. }\end{array}$ \\
\hline Flexibilidade & $\begin{array}{l}\text { Avaliou, de forma geral a } \\
\text { flexibilidade que jogo dispõe ao } \\
\text { jogador para alcançar o objetivo } \\
\text { através da customização dos } \\
\text { elementos de interface. }\end{array}$ \\
\hline $\begin{array}{l}\text { Considerações de Experiência } \\
\text { do Usuário }\end{array}$ & $\begin{array}{l}\text { Avaliou a qualidade do sistema } \\
\text { criado para o jogo em relação ao } \\
\text { nível de experiência do jogador. }\end{array}$ \\
\hline Adaptabilidade & $\begin{array}{l}\text { Avaliou, de forma geral, a } \\
\text { capacidade da interface do jogo } \\
\text { em se adaptar às necessidades } \\
\text { e preferências do jogador, } \\
\text { levando em consideração a sua } \\
\text { experiência. }\end{array}$ \\
\hline Proteção contra os erros & $\begin{array}{l}\text { Avaliou o mecanismo } \\
\text { de proteção contra erros } \\
\text { para prevenir possíveis } \\
\text { consequências desastrosas ou } \\
\text { não recuperáveis. }\end{array}$ \\
\hline Mensagens de erros & $\begin{array}{l}\text { Avaliou a qualidade das } \\
\text { mensagens de erro mostradas } \\
\text { ao jogador, levando em conta a } \\
\text { pertinência, a legibilidade e a } \\
\text { exatidão das informações. }\end{array}$ \\
\hline Correção de Erros & $\begin{array}{l}\text { Avaliou os meios colocados } \\
\text { à disposição do jogador para } \\
\text { correção dos erros encontrados. }\end{array}$ \\
\hline Gestão De Erros & $\begin{array}{l}\text { Avaliou, de forma geral, } \\
\text { capacidade do jogo em oferecer } \\
\text { mecanismos de prevenção } \\
\text { contra erros, de informá-los e } \\
\text { meios para corrigí-los. }\end{array}$ \\
\hline $\begin{array}{l}\text { Homogeneidade / Consistência } \\
\text { (Coerência) }\end{array}$ & $\begin{array}{l}\text { Avaliou a qualidade dos } \\
\text { elementos da interface em se } \\
\text { apresentem de forma idêntica } \\
\text { em contextos idênticos e } \\
\text { diferentes em contextos } \\
\text { diferentes. Avaliando os } \\
\text { rótulos, os formatos e as tarefas. }\end{array}$ \\
\hline Significados & $\begin{array}{l}\text { Avaliou os elementos de } \\
\text { informação quanto aos } \\
\text { significados dos códigos e } \\
\text { denominações, presentes na } \\
\text { interface do jogo. }\end{array}$ \\
\hline
\end{tabular}

Compatibilidade

Avaliou, de forma geral, o quão compatível é o jogo em relação a diversos perfis de jogador.

Quadro 2: Conjunto de critérios ergonômicos que avaliou a qualidade da funcionalidade dos elementos presentes na interface. Fonte: critérios ergonômicos adaptados de BASTIEN e SCAPIN (1993).

A interatividade foi avaliada com base nas recomendações apresentados por Saffer (2008), contextualizando-as de forma análoga ao universo dos jogos digitais, conforme quadro 3.

\begin{tabular}{|c|c|}
\hline Recomendações & Conceito \\
\hline Perceptibilidade & $\begin{array}{l}\text { Avaliou o quão perceptível são os } \\
\text { objetos interativos que permitem } \\
\text { controlar as ações do jogo. }\end{array}$ \\
\hline Confiabilidade & $\begin{array}{l}\text { Avaliou o quão confiável } \\
\text { é a robustez da interface } \\
\text { disponibilizada ao jogador. }\end{array}$ \\
\hline Adequação & $\begin{array}{l}\text { Avaliou a adequação do conjunto } \\
\text { de gestos interativos oferecidos ao } \\
\text { jogador levando em consideração } \\
\text { o contexto de uso apropriado a } \\
\text { cultura local. }\end{array}$ \\
\hline Significância & $\begin{array}{l}\text { Avaliou o quão significativos são os } \\
\text { gestos interativos disponibilizados } \\
\text { ao jogador. }\end{array}$ \\
\hline Inteligência & $\begin{array}{l}\text { Avaliou o quão inteligente é o } \\
\text { jogo em armazenar e processar as } \\
\text { informações. }\end{array}$ \\
\hline Esperto & $\begin{array}{l}\text { Avaliou o quão esperta é a } \\
\text { interface a prever e auxiliar o } \\
\text { jogador a realizar uma tarefa } \\
\text { quando necessário }\end{array}$ \\
\hline Divertimento & $\begin{array}{l}\text { Avaliou o quão divertido e } \\
\text { envolvente são os gestos interativos } \\
\text { disponibilizados ao jogador. }\end{array}$ \\
\hline Estética & $\begin{array}{l}\text { Avaliou o quão agradável } \\
\text { esteticamente é a interface gestual } \\
\text { disponibilizada ao jogador. }\end{array}$ \\
\hline Ética & $\begin{array}{l}\text { Avaliou o quão ético a interface } \\
\text { gestual se apresenta a ponto } \\
\text { de não causar nenhum tipo de } \\
\text { constrangimento ao jogador. }\end{array}$ \\
\hline Interatividade & $\begin{array}{l}\text { Avaliou, de forma geral, a } \\
\text { interatividade da interface gestual } \\
\text { oferecida ao jogador. }\end{array}$ \\
\hline
\end{tabular}

Quadro 3: Conjunto de recomendações para avaliar a qualidade da interatividade na interface gestual oferecida ao jogador. Fonte: recomendações adaptadas de SAFFER (2008). 


\section{Conclusão}

Os resultados desta pesquisa permitiram anexar um conjunto de conhecimentos ligados à área de Design de Interface em jogos digitais para plataforma mobile que podem ser consultados por discentes e docentes, como fonte de pesquisa no ensino e aprendizagem, ou por profissionais, em projetos de interface de jogos digitais no mercado. Assim como, incentiva a pesquisa por novos conhecimentos que venham promover avanços na qualidadedodesign deinterfaceem jogos digitais. Neste aspecto, ressaltou-se que o desenvolvimento de jogos digitais para smartphones obedecem a diferentes planos, oportunizando, futuramente, uma adaptação a uma linguagem mais próxima ao universo dos jogos digitais, conforme modelo proposto por Garrett (2011). Espera-se também, demonstrar a importância das relações estabelecidas através dos conhecimentos aqui estudados para o desenvolvimento de design de interface em jogos digitais para plataforma mobile. Por fim, disponibilizou uma ferramenta capaz de atender as necessidades de conhecimentos sobre como projetar e avaliar sistematicamente padrões de interfaces sensoriais a aspectos de jogabilidade, ergonomia, e interatividade, na perspectiva quanto método de avaliação, passando a oferecer um novo referencial teórico para futuras pesquisas na área e acesso as diversas relações conforme enfoque desejado.

\section{Referências}

Bastien, C. e Scapin, D. (1993). Critérios Ergonômicos para Avaliação de Interfaces Homem - Computador. Disponível em: <http://www.labiutil.inf.ufsc.br/ergolist/ >. Acessado em: 14 de agosto de 2014.

Bastien, C. SCAPIN, D. (1993).Ergonomic criteria for the evaluation of human-computer interfaces. INRIA.

Dixon, C. (1995). Why we need to reclassify type. Eye 19: 8687.

Ergolist. Disponível: http://www.labiutil.inf.ufsc.br/ergolist/ check.htm
Farina, M (2006). Psicodinâmica das cores em comunicação. São Paulo: Edgard. Blusher.

Fontoura, A. e Fukushima, N. Vade-mécum de tipografia. ( 2015). Curitiba: Insight Editoral.

Frase, T. e Banks, A. (2007). Guia Completo da Cor. $2^{\mathrm{a} e d . ~ S a ̃ o ~}$ Paulo: Senac Editora.

Garrett, J. J. (2011). The elements of user experience: user centered design for web and beyond. $2^{\mathrm{a} e d .}$ New York: New Riders Press.

Neil, T. (2012). Padrões de design para aplicativos móveis. São Paulo: Novatec.

Pedrosa, I. (2009). Da cor à cor inexistente. $10^{\mathrm{a} e d . ~ R i o ~ d e ~}$ Janeiro: Senac Nacional.

Perassi, R. (2007). Gramática Comparada da Representação Gráfica. Revista Convergência. Disponível em: http:// convergencias.esart.ipcb.pt/artigo.php?id=92

Pereira, A. e Gonçalves, M. Hipermídia e Multimídia. Disponível Em: http://www.avaad.ufsc.br/hiperlab/avaad/ moodle/file.php/392/multimidia_e_hipermidia/fhadg_ multimidia_e_hipermidia.pdf

Rogers, S. (2010). Level Up! The Guide to Great Video Game Design. 1. ed. Chichester: John Wiley \& Sons.

Saffer, D. (2008). Designing Gestural Interfaces. Canda: O’Reilly Media, Inc.

Schell, J. (2011). A Arte de Game Design: o livro original, (The Art of Game Design: A book of lenses), Rio de Janeiro, RJ: Elsevier Editora Ltda.

Samara, T. (2010). Ensopado de Letra. São Paulo, SP: Edgard Blücher, Editora.

Saunders, K.; Novak, J. (2013). Game development essentials: game interface design. $2^{\mathrm{a} e d . ~ A u s t r a ́ l i a: ~ C e n g a g e ~ L e a r n i n g . ~}$

Rabin, S. (2012). Introdução ao Desenvolvimento de Games. São Paulo, SP: Cengage Learning.

Whitmore, G. (2003). Design With Music In Mind: A Guide to Adaptive Audio for Game Designers. Disponível em: www. gamasutra.com/resource_guide/20030 528/whitmore_01. shtml 